\title{
Metacercárias (Platyhelminthes: Digenea) em ESPÉCIES DE PEIXES ORNAMENTAIS de água doce no Sudeste do Brasil: relato de caso
}

\section{Metacercariae (Platyhelminthes: Digenea) in freshwater orna- mental fish species in southeastern Brazil: case report}

\author{
Pedro Henrique Magalhães Cardoso ${ }^{1}$ \\ Avenida Prof. Dr. Orlando Marques de Paiva, 87, Butantã, São Paulo, SP, Brasil - CEP: 05508-270. \\ E-mail: pedrohenriquemedvet@usp.br
}

DOMINGUEZ, H.N. ${ }^{1}$; BALIAN, S.C. ${ }^{1}$; TANCREDO, K.R. ${ }^{2}$; MARTINS, L.M. ${ }^{2}$

\begin{abstract}
Como citar: DOMINGUEZ, Heloisa Nunes et al. Metacercárias (Platyhelminthes: Digenea) em espécies de peixes ornamentais de água doce no Sudeste do Brasil: relato de caso. Revista de Educação Continuada em Medicina Veterinária e Zootecnia do CRMV-SP, São Paulo, v.18, n. 1, 2020. Doi.10.36440/recmvZ.v18i1.37997

Cite as: DOMINGUEZ, Heloisa Nunes et al. Metacercariae (Platyhelminthes: Digenea) in fish species freshwater ornamental in southwastern Brazil: case report. Journal of Continuing Education in Animal Science of CRMV-SP, São Paulo, v.18, n.1, 2020. Doi.10.36440/recmvz.v18i1.37997
\end{abstract}

\section{Resumo}

Metacercárias são larvas de trematódeos digenéticos comumente encontradas encapsuladas em brânquias, pele, músculos e órgãos internos. Geralmente não são prejudiciais aos animais quando em baixo número, porém, em altas infestações podem levar a óbito. 0 presente estudo relata infecções por metacercárias em 58 peixes ornamentais de água doce, provenientes de produtores de dois municípios do estado de São Paulo (Iguape e Jacareí), sudeste do Brasil. Após a análise, 13\% dos animais (8/58) apresentaram metacercárias encistadas no tecido subcutâneo e 43\% (25/58) apresentaram metacercárias encapsuladas em brânquias. Estes resultados destacam a importância do controle sanitário de peixes e na realização de diagnósticos que possam desenvolver programas de biosseguridade no cultivo de peixes ornamentais. É discutida a importância de assegurar a sanidade de peixes ornamentais de forma a tornar a atividade economicamente viável e reduzir perdas econômicas na produção.

Palavras-chave: Peixes ornamentais. Diagnóstico. Metacercárias. Biosseguridade.

1 Departamento de Medicina Veterinária Preventiva e Saúde Animal, Faculdade de Medicina Veterinária e Zootecnia da Universidade de São Paulo, São Paulo, SP, Brasil

2 Laboratório AQUOS-Sanidade de Organismos Aquáticos, Departamento de Aquicultura, Universidade Federal de Santa Catarina, Florianópolis, SC, Brasil 


\section{Abstract}

Metacercariae are digenetic trematode larvae commonly encapsulated in gills, skin, muscles and internal organs and are generally not harmful to animals when in low numbers, but in high infestations can lead to death. The present study reports metacercariae infections in 58 freshwater ornamental fishes from producers in two municipalities of the state of São Paulo (Iguape and Jacareí), Southeastern Brazil. After analysis, $13 \%$ of the animals (8/58) had metacercariae encysted in subcutaneous tissue and $43 \%(25 / 58)$ presented metacercariae encapsulated in gills. These results highlight the importance of the Veterinary in the sanitary control of fish, with the ability to identify agents, establish diagnoses and from there develop biosecurity control programs in the production systems of ornamental aquatic organisms, in order to ensure the viability of the fish business, promote animal welfare, reduce manageable losses and contribute to its role for animal and environmental health as a whole.

Keywords: Ornamental fish. Diagnosis. Metacercariae. Biosecurity.

\section{Introdução}

0 mercado de peixes ornamentais vem crescendo substancialmente nas últimas décadas (FAO, 2010; 2018) e no Brasil também é observado um desenvolvimento da aquicultura nos últimos anos devido à intensificação do setor (PORTZ et al., 2013). Apesar do contínuo crescimento produtivo, ainda ocorre o comércio e a circulação de animais vivos sem o cumprimento de procedimentos técnicos padronizados e seguros, práticas que facilitam a disseminação de inúmeros agentes causadores de doenças infecciosas e sérios problemas sanitários em regiões indenes, além de provocar situações estressantes aos animais, levando-os à taxas de mortalidade e expressão de doenças totalmente evitáveis (CARDOSO; BALIAN, 2018; CARDOSO et al., 2019). Entre estes agentes estão as metacercárias, vermes encapsulados comumente encontrados em peixes ornamentais criados em tanques ou viveiros com acesso a outros hospedeiros, como crustáceos, moluscos, aves e mamíferos.

Metacercárias são larvas de trematódeos digenéticos com distribuição mundial que infectam diferentes hospedeiros intermediários e definitivos. Podem ser encontradas na pele, brânquias e órgãos internos dos peixes e, geralmente, não são prejudiciais aos mesmos quando em baixo número, porém, em infestações maciças provocam debilitação e até a morte (DIAS et al., 2003).

Os trematódeos digenéticos possuem ciclo de vida complexo (Figura 1). Moluscos e crustáceos são os hospedeiros intermediários; aves e mamíferos piscívoros atuam como hospedeiros definitivos. Os peixes atuam tanto como hospedeiros intermediários (portadores de metacercárias), quanto definitivos. Os digenéticos adultos presentes no intestino de aves liberam ovos junto com as fezes de aves e/ou mamíferos que, na água, se transformam em miracídios. Os miracídios por sua vez infectam moluscos e crustáceos. Nos hospedeiros intermediários, os miracídios mudam de estágio para cercárias, que deixam o hospedeiro intermediário à procura do tecido alvo dos hospedeiros definitivos e/ou intermediário. Ao atingir os peixes, as cercárias se diferenciam em metacercárias, que podem tanto encapsular e permanecer encistadas por longos períodos no peixe, como se diferenciar em um verme adulto depois que o peixe é predado pelo seu hospedeiro definitivo (NOGA, 2010).

0 presente relato descreve a ocorrência de infestações por metacercárias em peixes ornamentais, de água doce, provenientes de produtores de dois municípios do estado de São Paulo (Iguape e Jacareí). Também destaca a importância do profissional médico-veterinário no controle sanitário de peixes, com capacidade para identificar agentes, estabelecer diagnósticos e a partir daí, desenvolver programas de controle de biosseguridade nos sistemas produtivos de organismos aquáticos ornamentais. 
Figura 1. Ciclo de vida de trematódeos digenéticos infectando peixes

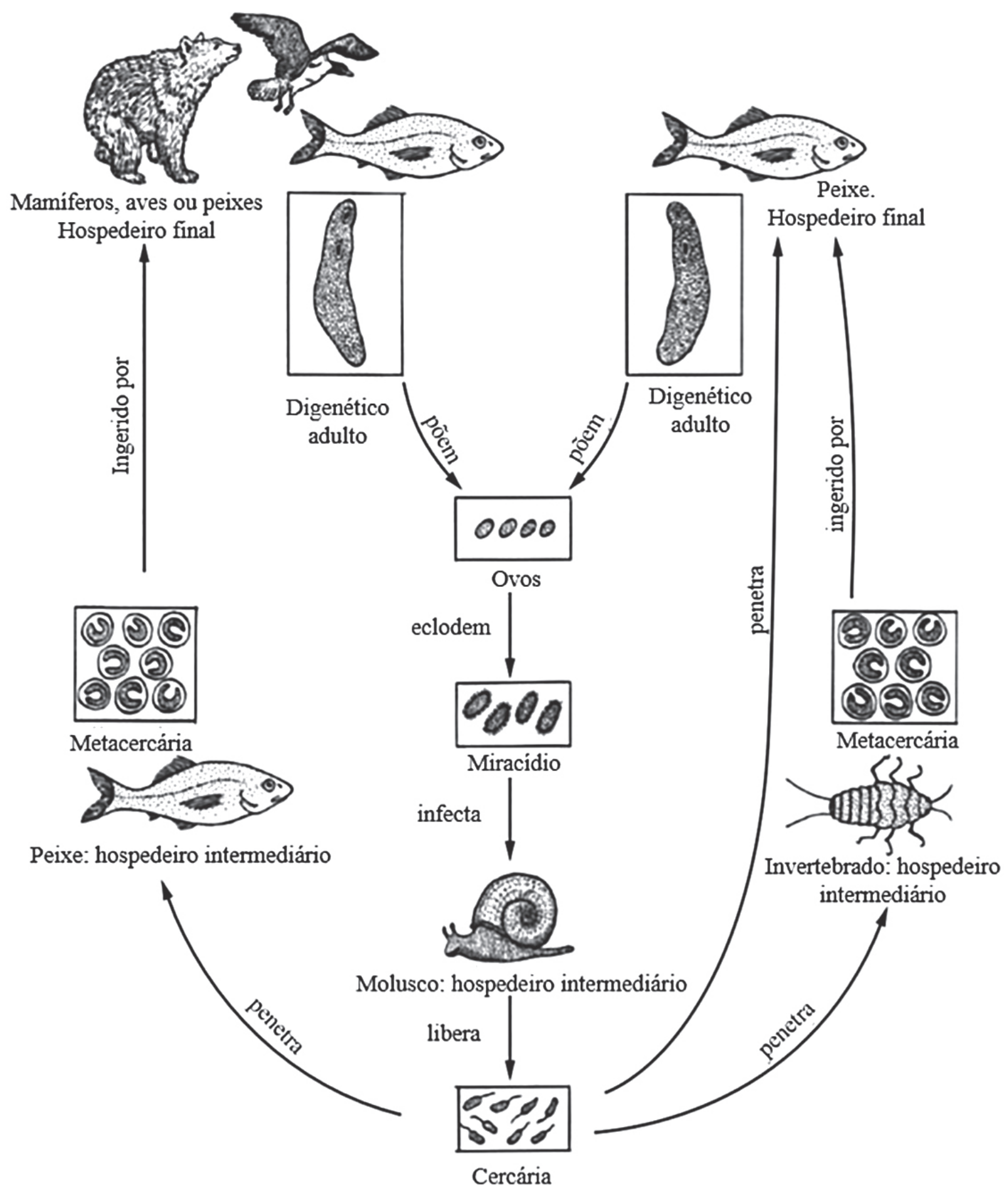

Fonte: Adaptado de Noga (2010). 


\section{Descrição do caso}

Entre novembro de 2018 e março de 2019, 58 peixes ornamentais de água doce oriundos de produtores de Iguape e Jacareí, ambos do estado de São Paulo, foram avaliados para a pesquisa de metacercárias. Ambas as pisciculturas cultivavam os peixes em tanques escavados abertos, sem proteção, permitindo o acesso de aves, moluscos e crustáceos, segundo relato dos produtores. Dentre as espécies acometidas estavam Kinguio Carassius auratus $(n=27)$, Corydora pimenta Corydora paleatus $(n=5)$, Tetra Preto Gymnocorymbus ternetzi $(n=2)$, Dojô Misgurnus anguillicaudatus $(n=1)$, Tetra Vidro Indiano Parambassius ranga $(n=6)$ e Plati Xiphophorus maculatus $(n=17)$. Os peixes foram anestesiados com Eugenol ( $75 \mathrm{mg} \mathrm{L}^{-1)}$ (ROUBACH et al., 2005) diluído em um recipiente de 4 L por 10 à 20 minutos e eutanasiados por secção da medula espinhal (EIRAS et al., 2000; JERÔNIMO et al., 2011). Na sequência, foi realizado o raspado de pele e a coleta de brânquias e órgãos internos para a pesquisa de parasitas por avaliação microscópica. Todos os procedimentos realizados com os animais tiveram aprovação do Comitê de Ética no Uso de Animais da Faculdade de Medicina Veterinária e Zootecnia da Universidade de São Paulo (Protocolo de Aprovação no: 8380210119 CEUA FMVZ USP). Como resultados, 13\% (8/58) dos animais apresentaram metacercárias encistadas em musculatura (Figuras 2a e 2b) e 43\% (25/58) apresentaram metacercárias encapsuladas em brânquias (Figuras 2c e 2d). A análise morfológica das metacercárias encistadas no tecido subcutâneo levou ao diagnóstico sugestivo do gênero Clinostomum (Figura 3).

Figura 2
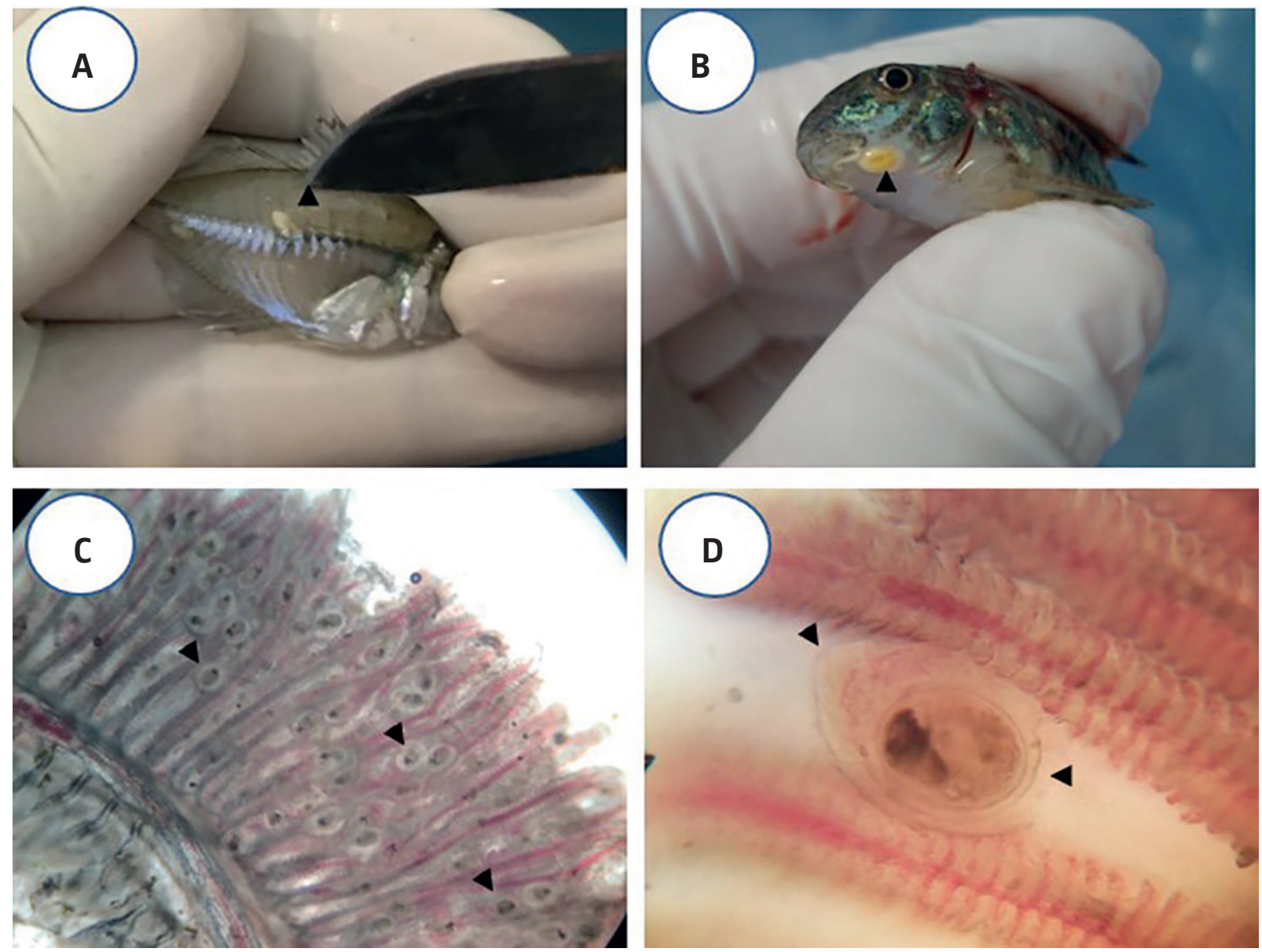

Fonte: Dominguez (2019).

Legenda 2. Metacercária encistada no tecido subcutâneo de Parambassius ranga (a), Corydora paleatus (b) e metacercárias encapsuladas em brânquias de Xiphophorus maculatus [objetiva de 4x] (c) e de Carassius auratus [objetiva de $20 x$ ] (d) 
Figura 3. Metacercária sugestiva do gênero Clinostomum corada com Carmalúmen de Mayer

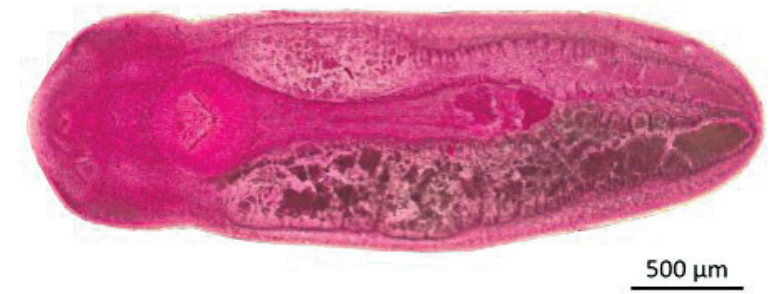

Fonte: AQUOS - Laboratório de Sanidade de Organismos Aquáticos. Departamento de Aquicultura, Universidade Federal de Santa Catarina (2019).

\section{Discussão e conclusão}

A presença de metacercárias em todos os animais examinados é um indicador da ocorrência de falhas graves de biosseguridade nas criações. Peixes infectados com uma grande quantidade de larvas podem não apresentar sinais clínicos devido à uma relação estável entre o hospedeiro e o parasita. Porém, apesar de inofensivas, as larvas encistadas podem descaracterizar o peixe, deixando-o com aspecto repugnante, não estético, dificultando sua comercialização (NOGA, 2010).

Nos peixes debilitados, as metacercárias podem desencapsular, e os parasitas livres na cavidade abdominal podem causar agravos severos, levando o hospedeiro à morte. Quando presentes nas brânquias, como no caso do Centrocestus formosanus, as metacercárias causam morbidade e mortalidade significativas, pois elas são responsáveis por reação condroplásica nas brânquias, resultando em formação de cartilagem ao redor de cada parasita (GONZÁLES; BECKER; HUTSON, 2018). A inflamação pode estar presente prejudicando severamente a estrutura e a função da brânquia; além disso, infecções bacterianas secundárias podem ocorrer, predispondo o peixe a outras doenças (PIAZZA et al., 2006; CARDOSO; COSTA; BALIAN, 2018).

Metacercárias do gênero Clinostomum podem formar nódulos em órgãos dos peixes como pele, cavidade oral, olhos, tecido subcutâneo, gônadas, intestinos, fígado, nadadeiras e músculos (PAVANELLI; EIRAS; TAKEMOTO, 2002). Alguns peixes podem se tornar resistentes à infecção pelas larvas de metacercárias, de modo a não apresentarem sintomatologia. Contudo, em alguns casos estas larvas podem desencapsular e penetrar órgãos vitais, levando o hospedeiro a óbito. De maneira geral, a infecção altera a alimentação do peixe, prejudica o ganho de peso e a fertilidade, podendo debilitá-lo até à morte, acarretando perdas econômicas ao produtor (SUTILI; GRESSLER; PELEGRINI, 2014).

Como as metacercárias estão encapsuladas nos peixes, o tratamento não é eficaz (BASSLER, 2011). Portanto, o correto é a tomada de medidas preventivas para evitar a ocorrência da doença, eliminando os hospedeiros intermediários e impossibilitando o acesso das aves nos tanques de criação. É fundamental a adoção de boas práticas de manejo e medidas de biosseguridade capazes de reduzir significativamente a incidência desta parasitose nos sistemas de produção de peixes ornamentais. 0 controle sanitário também assegura melhores condições de produção e qualidade para outros elos da cadeia de peixes ornamentais.

Destaca-se nesse contexto a importância de profissionais técnicos como o médico-veterinário, atuando em todos os segmentos da aquariofilia, estabelecendo condutas e criando barreiras de proteção sanitária. Esse profissional atuando conjuntamente com outros técnicos do setor é capaz de planejar, implementar e manter programas de controle e prevenção de doenças no sistema produtivo, prevenindo e controlando parasitoses como esta, entre outras afecções. Como consequência, está o benefício de todos os envolvidos, isto é, os animais poderiam sair das fazendas e chegar aos distribuidores, lojas e residências, saudáveis e com melhor qualidade de vida. 


\section{Referências}

BASSLER, G. Guia prático de doenças de peixes ornamentais tropicais e de lagos (e de camarões ornamentais). Bélgica: Bassleer Biofish, 2011.

CARDOSO, P. H. M.; BALIAN, S. C. Manual técnico de controle sanitário para peixes ornamentais: criação e implementação de programas de autocontrole com base no sistema APPCC. São Paulo: Universidade de São Paulo. Faculdade de Medicina Veterinária e Zootecnia, 2018. Disponível em: http://www. livrosabertos.sibi.usp.br/portaldelivrosUSP/catalog/view/219/199/923-1. Acesso em: 28 set. 2019

CARDOSO, P. H. M.; COSTA, A. R.; BALIAN, S. C. Ectoparasitic fauna in freshwater ornamental fish acquired by a wholesaler in the city of São Paulo. Brazilian Journal of Veterinary Research and Animal Science, v. 55, n. 4, p. 1-6, 2018.

CARDOSO, P. H. M. et al. Doenças infeciosas em peixes ornamentais de aquário: medidas de prevenção e controle. Brazilian Journal of Veterinary Research and Animal Science, v. 56, n. 2, 2019.

DIAS, M. L.G.G. et al. The life cycle of Clinostomum complanatum Rudolphi, 1814 (Digenea, Clinostomidae) on the floodplain of the high Paraná river, Brazil. Parasitology Research, v. 89, p. 506-508, 2003.

EIRAS, C. J.; TAKEMOTO, R. M.; PAVANELLI, G. C. Métodos de estudo e técnicas laboratoriais em parasitologia de peixes. Maringá: Eduem, 2000.

FAO - Food and Agriculture Organization of the United Nations. Production and commerce of ornamental fish: technical-managerical and legislative aspects. Rome, 2010.

FAO - Food and Agriculture Organization of the United Nations. The state of world fisheries and aquaculture 2018: meeting the sustainable development goals. Rome, 2018.

GONZÁLES, A. T.; BECKER, J. A.; HUTSON, K. S. Parasite dispersal from the ornamental goldfish trade. Advances in Parasitology, v. 100, p. 239-281, 2018.

JERÔNIMO, G. T. et al. Circular Técnica 39: métodos para coleta de parasitos de peixes. Macapá, AP: EMBRAPA, 2011. Disponível em: https://ainfo.cnptia.embrapa.br/digital/bitstream/item/46620/1/ AP-2011-Metodos coleta-Circular.pdf. Acesso em: 28 set. 2019.

NOGA, E. J. Fish disease: diagnosis and report. 2. ed. lowa, EUA: Wiley-Blackwell, 2010.

PAVANELLI, G. C.; EIRAS, J. C.; TAKEMOTO, R. M. Doenças de peixes: profilaxia, diagnóstico e tratamento. 2. ed. Maringá: EDUEM, 2002.

PIAZZA, R. et al. Parasitic diseases of freshwater ornamental fishes commercialized in Florianópolis, Santa Catarina, Brazil. Boletim do Instituto de Pesca, v. 32, n. 1, p. 51-57, 2006.

PORTZ, L. et al. Parasitos de peixes de cultivo e ornamentais. In: Parasitologia de peixes de água doce do Brasil. Maringá: EDUEM, 2013. p. 85-114.

ROUBACH, R. et al. Eugenol as an efficacious anaesthetic for tambaqui, Colossoma macropomum (Cuvier). Aquaculture Research, v. 36, n. 11, p. 1056-1061, 2005.

SUTILI, F. J.; GRESSLER, L. T.; PELEGRINI, L. F. V. Clinostomum complanatum (Trematoda, Digenea): a parasite of birds and fishes with zoonotic potential in southern Brazil: a review. Revista Brasileira de Higiene e Sanidade Animal, v. 8, n. 1, p. 99-114, 2014. 